\title{
Этапы становления теории механической активности легких и их механического гомеостазиса
}

Кафедра пропедевтики внутренних болезней ГОУ ВПО "Сибирский государственный медицинский университет Федерального агентства по здравоохранению и социальному развитию": 634050, Томск, Московский тракт, 2

\section{F.F.Tetenev \\ Development of theory of pulmonary mechanical activity and mechanical homeostasis of the lung}

Key words: respiratory mechanics, elastic and inelastic resistance of the lung, tissue friction, asynphasic resistance, pulmonary mechanical activity, mechanical homeostasis of the lung.

Ключевые слова: биомеханика дыхания, эластическое и неэластическое сопротивление легких, тканевое трение, асинфазное сопротивление, механическая активность легких, механический гомеостазис легких.

В 2010 г. исполнилось 120 лет кафедре пропедевтики внутренних болезней Сибирского государственного медицинского университета, основанной в стенах Томского императорского университета, которую возглавил проф. Михаил Георгиевич Курлов - ученый, широко известный в России и за рубежом, создавший сибирскую клиническую школу.

В статье представлен обзор важнейших этапов становления нового представления о механике дыхания, разработанного сотрудниками кафедры, начиная с 1963 г., предпосылкой которого явились исследования функционального состояния аппарата внешнего дыхания (АВД) и системы кровообращения, которые проф. Б.М.Шершевский начал проводить в 1952 г. [1].

Общепринятое учение о механике дыхания основано на парадигме Ф.Дондерса, который в 1853 г. впервые научно доказал пассивную роль легких в механизме дыхательных движений [2]. Со времени появления методики измерения транспульмонального давления (ТПД) [3] некоторые исследователи обнаруживали явления, которые не укладывались в эту парадигму, однако отвергали их как артефакты [4-6]. Поколебать привычные представления о механике дыхания могли лишь факты, вступавшие в противоречие с парадигмой.

Гипотеза о существовании источника механической активности легких впервые была выдвинута в 1966 г. при исследовании статической растяжимости легких методом прерывания воздушного потока у здоровых людей [7], когда на кривой ТПД должно регистрироваться плато как обязательное требование дондерсовской парадигмы: ТПД не изменяется, если не изменяется объем легких. Клинико-экспериментальные исследования показали, что во время прерывания воздушного потока на вдохе давление в альвеолах падает в большей степени по сравнению с внутригрудным. Это смещает мембрану дифферен- циального датчика давления в зону положительного давления. При прерывании воздушного потока на выдохе давление в альвеолах повышается в большей степени, чем изменяется внутригрудное давление, и плато ТПД смещается в зону более отрицательного давления. Так было выявлено фундаментальное противоречие с парадигмой Ф.Дондерса: во время прерывания воздушного потока объем легких остается прежним, а ТПД изменяется, демонстрируя присасывающее действие легких на вдохе и сокращение - на выдохе. В эксперименте на животных было показано, что деформация плато ТПД однозначно зависела от экспираторного и инспираторного действия легких [7, 8].

При исследовании эластических свойств легких было выявлено еще одно существенное противоречие: у больных с обструктивными нарушениями механики дыхания на уровне спонтанного дыхания эластичность легких (ЭЛ) была повышена, тогда как общая ЭЛ - коэффициент ретракции легких (КРЛ), обратная величина общей растяжимости легких (ОРЛ) - существенно снижена. Объяснение этому явлению было дано в процессе исследования пациентов с бронхиальной астмой (БА) легкого течения [9], у которых динамическая растяжимость легких (ДРЛ) была снижена, а жизненная емкость легких (ЖЕЛ), форсированная жизненная емкость легких за 1 с и максимальная вентиляция легких в пределах допустимой нормы. Была высказана гипотеза, что повышение эластического сопротивления легких, т. е. ЭЛ, на уровне дыхательного объема было функциональным и обеспечивающим нормальные показатели вентиляционной функции легких. Разница между ДРЛ и ОРЛ является диапазоном функционального изменения ЭЛ. Был предложен коэффициент функциональной ЭЛ (КФЭЛ), который определялся делением ОРЛ на ДРЛ и показывал, в какой степени ЭЛ может увеличиваться от 
ОРЛ до ДРЛ для обеспечения механики спонтанного дыхания [10]. У здоровых людей КФЭЛ варьировался от 0,48 до $1,4(0,81 \pm 0,08)$, а у больных выраженной эмфиземой легких - от 4,92 до 29,22 (7,69 \pm 2,27). Таким образом, в существующее представление о факторах, определяющих величины показателей ЭЛ, было внесено дополнение. К известным факторам, способствующим снижению ДРЛ при спонтанном дыхании, был добавлен новый - функциональное повышение эластичности.

Интегральная ЭЛ тоже определяется этими факторами, однако при хронической обструктивной эмфиземе решающей является анатомическая утрата легкими эластичности. Острую обратимую гиперинфляцию легких, которая возникает при легком течении БА и при провокационных пробах, обусловливает функциональное снижение ЭЛ. Это явление наблюдали P.Macklem et al. [11, 12]. У больных эмфиземой под влиянием атропина происходило дополнительное обратимое (функциональное) уменьшение ЭЛ и увеличение общей емкости легких на фоне функционального снижения эластичности [13].

Общепринятым является представление об обструктивной природе гиперинфляции легких (ГЛ), согласно которому она возникает посредством вентильного механизма задержки воздуха в респираторной зоне легких (сужение мелких бронхов) либо изза снижения эластического напряжения легких. При этом эластические силы со стороны грудной клетки преобладают, и дыхательный объем смещается в зону резервного вдоха. Другим механизмом ГЛ следует считать гидропексический синдром, впервые описанный В.С.Суховским [14], возникающий у $54 \%$ беременных женщин, а также у лиц, вдыхающих дым лесных пожаров, и у курильщиков. Автор получил косвенные доказательства, что данный компонент механизма ГЛ имеет место и при хронической обструктивной болезни легких (ХОБЛ). Дополнительным механизмом ГЛ, очевидно, является описанное выше функционально обратимое изменение ЭЛ.

Проблемы измерения и оценки показателей общего неэластического сопротивления (ОНС) легких остаются не менее сложными. Структура ОНС легких включает в себя бронхиальное сопротивление (БС), тканевое трение (ТТ) и инерционное сопротивление (ИС). Значениями ТТ и ИС в механике дыхания обычно пренебрегают, и ОНС отождествляют с БС. Рассчитывается ОНС по отношению динамического компонента ТПД к скорости воздушного потока.

Прерывание воздушного потока на 0,5 с использовалось с целью более точного измерения альвеолярного давления для вычитания его из ТПД при определении статической растяжимости легких [4]. Поэтому было предложено применять данный метод для расчета БС [15]. Величины БС, полученные таким способом, в среднем достаточно хорошо согласуются с величинами БС, измеренными в плетизмографе тела (Raw) [16, 17]. Поскольку для определения БС с помощью ТПД требуется вводить исследуемому внутрипищеводной зонд, предпочте- ние отдается бодиплетизмографии. Между тем прерывание воздушного потока на 0,5 с на вдохе и выдохе позволяет выявить сложные для объяснения и парадоксальные факты.

При хронической эмфиземе легких был обнаружен т. н. эластический гистерезис (ЭГ) [18, 19], сущность которого рассматривали как проявление свойств сурфактанта - вплоть до того, что эти 2 понятия считали синонимами. Однако вполне логично было определять ЭГ как результат затраты работы дыхания на преодоление ТТ [18, 20-22]. Общий легочный гистерезис обусловлен затратой работы дыхания на преодоление ОНС, после вычитания из которого БС, должно оставаться ТТ. ИС при этом дифференцировать невозможно. Из 47 практически здоровых людей ТТ определялось у 4, не выявлялось у 15, а у остальных ЭГ был отрицательным [8]. Отсутствие ТТ можно было объяснить тем, что оно имело малую величину и не обнаруживалось при исследовании механики дыхания. Отрицательная же величина ТТ являлась парадоксом. Уменьшение ТТ может быть обусловлено проявлением тиксотропии, но отрицательная величина ТТ в любой механической системе невозможна без функционирования внутрисистемного источника механической энергии. Так возникла и далее разрабатывалась гипотеза о механической активности легких [18, 23].

Из 60 больных ХОБЛ с резко выраженной эмфиземой положительный ЭГ определялся у 55, не определялся - у 3 пациентов и был отрицательным - у 2. Сочетание повышения ЭГ со снижением ЭТЛ было предложено рассматривать в качестве облигатного признака хронической обструктивной эмфиземы легких [13]. Повышение ТТ при эмфиземе укладывалось в теоретические представления о жировой дегенерации гладкомышечных волокон легких [24] и снижении в связи с этим механической активности легких. У 91,6 \% больных с выраженной эмфиземой легких был положительный ЭГ, то есть - ТТ. У больных кардиогенным застоем в легких ТТ определялось в $61 \%$ случаев, у больных диффузным метатуберкулезным пневмофиброзом - в 43,2 \%, при пневмонии - в 36,4 \% и при БА - в 23,35\%.

Изучение ЭГ у здоровых людей позволило выявить парадоксальные факты, размышление над которыми привело к пересмотру структуры ОНС легких. У 10 хорошо подготовленных к исследованию здоровых добровольцев регистрировали спирограмму и ТПД при спонтанном дыхании, при ступенчатом, глубиной, равной ЖЕЛ, с произвольными остановками дыхания 3-4 раза на вдохе и выдохе, а также при прерывании воздушного потока клапаном 3-4 раза на вдохе и выдохе. Средняя скорость воздушного потока при 3 маневрах дыхания была одинаковой и составляла 10 л / мин. Описанное исследование предпринималось для изучения эластических свойств легких [25]. При ступенчатом дыхании БС практически отсутствовало, а ЭГ был небольшим и соответствовал ТТ. При прерывании воздушного потока ЭГ становился отрицательным, а ОНС значительно возрастало. Почему в равных условиях 
скорости воздушного потока при спонтанном дыхании БС имело известную величину, а при ступенчатом дыхании оно отсутствовало? В бронхиальном дереве аэродинамическое сопротивление было столь мало, что не улавливалось при регистрации ТПД. Второй вопрос был не менее неожиданным: почему при прерывании воздушного потока ОНС значительно возрастало, хотя скорость воздушного потока была прежней?

Позднее в результате обширных клинико-экспериментальных исследований Т.Н.Бодровой [26-29] было выявлено, что при ступенчатом дыхании остановка воздушного потока совершается произвольно и действие внутри- и внелегочного источников механической энергии осуществляется согласованно, синфазно. В связи с этим величина альвеолярного давления на вдохе и выдохе была минимальной и практически не улавливалась с помощью построения дыхательной петли и петли ЭГ. Дыхательная петля при этом численно составляла величину работы дыхания по преодолению ОНС. Поскольку БС в данном дыхательном цикле не определялось, дыхательная петля соответствовала ЭГ, т. е. ТТ. Эти результаты измерений были транспонированы на дыхательную петлю спонтанного дыхания с таким же МОД, что позволило пересмотреть структуру ОНС спонтанного дыхания у здоровых людей. БС у них было, очевидно, близким к нулю, ТТ составляло $1 / 3$ ОНС, а оставшиеся $2 / 3$ ОНС приходились на асинфазное сопротивление легких (АФС), которое возникало в результате асинхронного действия внутри- и внелегочного источников механической энергии и, по-видимому, могло выполнять роль инструмента поддержания механического гомеостазиса легких (МГЛ) [1].

Сущность данного механизма состоит в том, что в физиологических условиях АВД для системы регуляции дыхания должен предоставлять определенную величину ОНС. В связи с тем, что истинные величины ИС, ТТ и особенно БС весьма малы, АФС восполняет должную величину ОНС. Рассогласование действия внутри- и внелегочного источников механической энергии при этом является физиологическим. При повышении БС и / или ТТ работа внутрии внелегочного источников механической энергии становится синфазной и АФС исчезает. При этом возможно и повышение механической активности легких, в связи с чем ОНС первое время может оставаться на нормальном уровне. Показатели механики дыхания, которые определяются по ТПД и расходу воздуха, таким образом, фактически составляют остаток всех видов сопротивления легких, которые не преодолеваются внутрилегочным источником механической энергии.

При прерывании воздушного потока клапаном действие дыхательной мускулатуры не выявляется, т. к. усилие, направленное на преодоление препятствия на вдохе или на выдохе создает давление, которое прикладывается в одинаковой степени по обе стороны мембраны дифференциального датчика. Внутрилегочный же источник механической энер- гии, оказывая сопротивление клапану, продолжает действовать по 1 сторону мембраны. Возникает искусственное, вызванное прерыванием воздушного потока рассогласование действия внутри- и внелегочного источников механической энергии - АФС. Действие АФС при этом приводит к ложному уменьшению ТТ и ложному увеличению БС. В связи с этим при всех формах патологии, кроме эмфиземы, часто определяется отрицательный ЭГ. В силу того, что ТТ не может быть отрицательным, следует считать, что ТT в действительности было значительно больше, чем та величина, которую получали, используя методику прерывания воздушного потока. В нормальных условиях, как было отмечено, ТТ составляло $1 / 3$ ОНС. Истинную величину ТТ при патологии определить пока невозможно. Увеличение БС под влиянием прерывания воздушного потока тоже было ложным, искусственным за счет действия АФС, потому что к патологически повышенному БС добавлялось увеличение его за счет прерывания воздушного потока, которое производилось для измерения альвеолярного давления.

Следует добавить, что результаты измерения БС всеми известными способами (в т. ч. с помощью бодиплетизмографа) являются завышенными. Для измерения БС в бодиплетизмографе используется инспираторно-экспираторный маневр дыхательного движения при закрытом клапане. Фактически это соответствует методике определения альвеолярного давления с прерыванием воздушного потока. Тем не менее общепринятая трактовка БС в клинической физиологии дыхания в настоящее время вполне соответствует обструктивной теории нарушения функции АВД. Результаты же измерения ТТ являются, напротив, заниженными настолько, что оно может отсутствовать полностью, или даже быть отрицательным. Совершенно очевидно, что это парадокс, затрудняющий интерпретацию результатов измерения ТТ. Оно не может отсутствовать и, тем более, быть отрицательным. Однако если его невозможно измерить, оно не просто отсутствует - оно преодолевается функцией внутрилегочного источника механической энергии. Сопоставление величин БС и ТТ, полученных различными методами их измерения, производил В.В.Ларченко и не выявил существенной разницы [17]. При различных формах патологии ТТ определялось у большего числа исследуемых лиц по сравнению с практически здоровыми лицами. Поэтому в среднем ТТ было существенно повышенным при обструктивных и необструктивных формах патологии [8]. В связи с этим были предложены способы определения ТТ, оформленные патентами [30, 31]. При обструктивных заболеваниях легких ТТ может составлять, в среднем, до $54 \%$ ОНС [9, 16, 25]. При пневмонии и миопатии повышение ОНС происходит только за счет повышения ТТ [28, 32], а при кардиогенном застое в легких повышаются и ТT, и БС [29].

Изучение действия АФС легких позволило разработать способ определения величины механической активности легких [33], при котором используется 
построение петли ЭГ медленного глубокого дыхания, затем петли аэродинамического сопротивления по величинам альвеолярного давления, измеренного несколько раз на вдохе и выдохе методом прерывания воздушного потока на 0,5 с. Затем появились методы определения величины работы дыхания внутрилегочного источника механической энергии при спонтанном дыхании [34] и измерения величины суммарной работы дыхания внутри- и внелегочного источников механической энергии при спонтанном дыхании [35].

Исследование механики дыхания при очаговых поражениях легких (очаговый, инфильтративный туберкулез легких, пневмония) выявило значительное снижение ДРЛ и повышение ТТ, что характеризовало легкие в целом и соответствовало изменению их механических свойств при диффузных нарушениях (диффузном метатуберкулезном пневмофиброзе, кардиогенном застое) [8, 29, 36-38]. Природа генерализованных изменений легких при очаговых поражениях оставалась неясной. Недостаточно было объяснять этот феномен нарушением свойств сурфактанта в связи с влиянием на него общей реакции организма на очаговое воспаление, тем более что при пневмонии существенно повышались остаточный объем легких (ООЛ), ОНС при нормальной общей емкости легких (ОЕЛ) и БС [1, 32, 39].

Исследование регионарной механики дыхания по методике, разработанной А.В.Левченко [39], выявило новые факты, подтверждающие несовершенство дондерсовской парадигмы. Регитрировались регионарные дыхательные петли по 3 зонам обоих легких. В качестве регионарной спирограммы использовалась реограмма легких. ТПД регистрировалось соответственно уровням расположения датчиков объема. Дыхательные колебания ТПД в верхних, средних и нижних зонах в среднем были одинаковыми и т. н. градиент внутриплеврального давления не оказывал на них существенного влияния. ДО и ДРЛ существенно увеличивались сверху вниз, а ОНС уменьшалось [32, 40, 41]. Регионарная неравномерность механических свойств легких в норме была четко сбалансирована, что было отнесено к явлению регионарного МГЛ [41].

В этих результатах, в целом ожидаемых, проявилось несовершенство общепринятого представления о том, что в верхних зонах легких бронхи имеют больший просвет и БС в них должно быть меньше. Еще более непонятной была природа избыточной амплитуды ТПД над верхними зонами легких, в которых расход воздуха существенно меньше. С помощью компьютерного контроля колебаний давления и объема легких было обнаружено извращение дыхательных петель, т. е. регионарного общего ЭГ, отражающего величину регионарного ОНС. Отрицательный общий ЭГ в данных исследованиях был зарегистрирован при спонтанном дыхании преимущественно в верхних зонах без всякого вмешательства в виде прерывания воздушного потока. Этот феномен наблюдался у $1 / 2$ практически здоровых людей и доказывал регионарную механическую активность легких [41]. Данное наблюдение легло в основу способа измерения регионарной механической активности легких [43]. Однако это явление регистрировалось только у 50 \% практически здоровых лиц, у $29 \%$ больных пневмонией и у 23,8 \% пациентов с ХОБЛ. Было высказано предположение, что регионарная механическая активность легких является инструментом для поддержания регионарного МГЛ. При ХОБЛ выявлялось выравнивание регионарных механических свойств легких за счет усиления функции верхних отделов легких и использования в определенной степени резерва регионарной механической активности легких.

Как показали исследования T.С.Агеевой [32, 43, 44], у пациентов с внебольничной пневмонией (ВП) повышение интегральных значений ОНС за счет повышения ТТ при нормальном БС сопровождалось качественными и количественными различиями регионарных ОНС как в месте локализации воспалительного инфильтрата, так и в остальных зонах пораженного и интактного легкого. При локализации инфильтрата в нижней доле правого легкого в ней было повышено ОНС на выдохе. В средней зоне правого легкого ОНС было повышено на вдохе и выдохе. В верхней зоне правого легкого и во всех зонах левого легкого ОНС в среднем соответствовало нормальному значению. При локализации инфильтрата в нижней доле левого легкого в нижней зоне было повышено ОНС на вдохе и выдохе. В нижней зоне правого легкого ОНС было повышено на выдохе, а в средней и верхней зоне - как на вдохе, так и на выдохе. Нормальные величины регионарного ОНС были только в средней и верхней зонах левого легкого. Причина описанного распределения значений ОНС по зонам легкого остается загадкой. С помощью вентиляционно-перфузионной пульмоносцинтиграфии у этих больных ВП было обнаружено в среднем равномерное по всем зонам легких повышение альвеолярно-капиллярной проницаемости. Этот факт позволял объяснить повышение интегрального значения ТТ и снижение растяжимости легких, однако в отдельных зонах легких ОНС было нормальным и даже отрицательным. По-видимому, регионарная механическая активность легких обеспечивала преодоление повышенного ОНС в соответствующих зонах [45].

Отрицательный общий ЭГ при спонтанном дыхании определялся исключительно редко, поэтому извращение дыхательной петли спонтанного дыхания первое время считали артефактом. Позднее были выявлены т. н. аномальные дыхательные петли, в которых отсутствовала либо инспираторная, либо экспираторная часть, либо дыхательная петля в целом, сюда же вошли случаи с отрицательным общим ЭГ. Из 44 больных диффузным метатуберкулезным пневмофиброзом они были у 2; из 43 больных БА у 3 ; из 71 больных ВП - у 13, из 70 больных прогрессирующей мышечной дистрофией - у 16 человек [46]. В эксперименте на животных извращение дыхательной петли спонтанного дыхания отмечалось в 6 из 8 случаев [8]. Анализ дыхательных петель 
больных ВП, в которых время выдоха было меньше времени вдохе или было равным таковому, позволил выявить необычное увеличение неэластической фракции работы дыхания на вдохе при нормальном БС и объяснить этот феномен повышеним ТТ в результате проявления антитиксотропии [13, 39]. Явление тиксотропии ранее было исследовано построением ЭГ и общего ЭГ у больных эмфиземой легких при различной скорости воздушного потока. При большей скорости воздушного потока ЭГ (ТT) уменьшался [8, 13].

Вопросы регуляции дыхания в клинике и эксперименте изучал А.И.Карзилов [47-50]. Была сформулирована концепция биомеханического гомеостазиса АВД в целом, построена биомеханическая модель легких, в которой нашла свое место и классическая модель Ф.Дондерса (внешний контур, ограниченный плеврой), и модель легких, обладающих самостоятельной механической активностью (внутренний контур - внутренняя поверхность дыхательных путей и респираторной зоны). Внешний контур относительно жестко связан с грудной клеткой и отражает действие внелегочного источника механической энергии (дыхательной мускулатуры). Внутренний контур легких обладает большей степенью свободы по отношению к внешнему благодаря действию внутрилегочного источника механической энергии. Именно такая модель легких может обеспечить гомеостатические свойства АВД. Разрабатывая проблему регуляции дыхания, А.И.Карзилов предложил новую методологию поиска и изучения гомеостатических параметров с жесткой регуляцией и параметров с пластической регуляцией. До настоящего времени гомеостазис исследовали на животных в условиях "жизнь-смерть" при отклонении параметров от физиологических значений. Для клинических исследований это абсолютно неприемлемо. Для сравнительного анализа значений показателей механики дыхания были обследованы здоровые люди с высоким уровнем резерва вентиляции легких, больные БА и ХОБЛ с низким уровнем резерва. Производился поиск кандидатных гомеостатических параметров, внутригрупповое и межгрупповое тестирование устойчивости параметров биомеханики дыхания при чрезкожной электростимуляции диафрагмы с итоговой оценкой кандидатных гомеостатических параметров путем расчета индекса гомеостатичности. В результате были определены гомеостатические показатели с жесткой и пластичной регуляцией, которые являются устойчивыми и выполняют роль функционального "скелета", "камертона" самонастройки системы АВД. Механическая активность легких является инструментом адаптации этой системы к изменяющимся условиям функционирования, что обосновывает функциональную необходимость наличия самостоятельной механической активности как неотъемлемого свойства легких.

Таким образом, результаты многолетних целенаправленных клинико-экспериментальных исследований, наблюдения и поиска способов объясне- ния природы парадоксальных явлений механики дыхания привели к созданию новой теории механической активности легких и механического гомеостазиса АВД, которые являются основанием для развития нового направления клинической физиологии дыхания, фундаментальный аспект которого состоит в изучении морфологии и функции источника механической энергии в легких. Реализация этого направления предполагает создание новых технологий, включая неинвазивный способ измерения показателей механики дыхания, новую систему показателей механики дыхания, а также их семиологию.

\section{Литература}

1. Тетенев Ф.Ф. Новые теории - в XXI век. 2-е изд. Томск: Изд-во Томск. ун-та; 2003.

2. Ландау Л. Учебник физиологии человека с включением гистологии и микроскопической анатомии и в применении к практической медицине доктора L. Landois (проф. физиологии и директора физиологического института в Грейфсвальде): 3-е изд.: Пер. с нем. Харьков: Изд. "Харьков"; 1898.

3. Neergaardt K., Wirz K. Über eine Methode zur Messung der Lunggenelastizitat am lebeden Menshen, inbesondere beim Emphysem. Z. Klin. Med. 1927; 105: 35-50.

4. Stead W., Fry D., Ebert R. The elastic properties of the lung in normal men and in patients with emphysema. J. Lab. Clin. Med. 1952; 40: 674-681.

5. Wohe M., Turner J., Mead J. Static volume-pressure curves of dog lungs in vivo and in vitro. J. Appl. Physiol. 1968; 24 (3): $348-354$.

6. Webb W., Smith J., Campbell G. Peri-alveolar pressure. Ann. Surg. 1961; 153 (5): 650-657.

7. Тетенев $Ф . Ф$. Деформация плато транспульмонального давления при экспериментальной эмфиземе легких. Бюл. экспер. биол. 1978; 9: 265-267.

8. Тетенев Ф.Ф. Биомеханика дыхания. Томск: Изд-во Томск. ун-та; 1981.

9. Тетенев К.Ф. Биомеханика дыхания при бронхиальной астме: Автореф. дис. ... канд. мед. наук. Томск; 1998.

10. Пат. № 2295286 Россия. Способ оценки функционального состояния легочной ткани / Тетенев Ф.Ф., Тетенев К.Ф., Бодрова Т.Н. // Бюл. открытий и изобрет. 2007; 8 .

11. Macklem P. Respiratory mechanics. Annu. Rev. Physiol. 1978; 40: 157-184.

12. Macklem P., Murphy M., Christie R. The work of breathing in health and disease. Amer. J. Med. 1974; 57 (10): 371-377.

13. Тетенев Ф.Ф. Особенности механики дыхания при различных формах патологии бронхолегочной системы. Обоснование гипотезы о механической активности легких: Автореф. дис. ... д-ра мед. наук. Казань; 1976.

14. Суховский В.С., Суховская В.В., Куперт А.Ф. Клиникодиагностические параллели между частотой развития гестоза, нарушением состояния плода и изменением отдельных параметров биомеханики дыхания у беременных женщин. Сиб. мед. журн. 2001; 3: 28-34.

15. Fry D., Ebert R., Stead W. et al. The mechanics of pulmonary ventilation in normal subjects and in patients with emphysema. Am. J. Med. 1954; 16 (1): 80-97.

16. Вотчал Б.Е., Магазанник Н.А. О достоверности измерения внутриальвеолярного давления методом прерывания. Мед. техника 1970; 1: 8-11. 
17. Ларченко В.В. Тканевое неэластическое сопротивление легких у больных хронической обструктивной болезнью и внебольничной пневмонией: Автореф. дис. ... канд. мед. наук. Томск; 2009.

18. Тетенев $Ф . \Phi$. Механика дыхания при эмфиземе легких: Автореф. ... канд мед. наук. Томск; 1966.

19. Ehrner L. Lung complicance and respiratory resistance, determined from timo-marked esophageal pressure-tidal volume surve and their relation to some other tests of lung function. Acta Med. Scand. 1960; 167 (suppl. 353): 3-220.

20. Bachofen $H$. Kung tissue resistance in normal and asthmatic subjects. Helv. Med. Acta. 1966; 33: 108-121.

21. Тетенев Ф.Ф. Эластические свойства легких при эмфиземе. Тер. арх. 1970; 3: 49-53.

22. Тетенев Ф.Ф. Легочный эластический гистерезис в норме и при эмфиземе. Бюл. экспер. биол. 1974; 6: 21-23.

23. Тетенев Ф.Ф. Обструктивная теория нарушения внешнего дыхания. Состояние, перспективы развития. Бюл. Сиб. мед. 2005; 4: 14-26.

24. Есипова И.К. (ред.). Легкое в патологии. Часть 1: Нарушение аэрации, воспалительные и опухолевые заболевания. Новосибирск: Изд-во "Наука", Сиб. отд-ние; 1975.

25. Тетенев Ф.Ф., Бодрова Т.Н. Новое представление о структуре неэластического сопротивления легких. Сиб. мед. журн. 1999; 3: 23-27.

26. Бодрова T.Н. Недостаточность внешнего дыхания. Новое представление о структуре неэластического сопротивления легких при различных заболеваниях (клинико-экспериментальное исследование): Автореф. дис. ... д-ра мед. наук. Томск; 1993.

27. Тетенев Ф.Ф., Бодрова Т.Н. Определяет ли система плевральных листков парадоксальные явления в механике дыхания. Бюл. экспер. биол. 1997; 10: 384-387.

28. Тетенев Ф.Ф., Бодрова Т.Н., Емельянова Н.В. Биомеханика дыхания у больных прогрессирующей мышечной дистрофией. Журн. неврол. и психиатр. 2000; 8: 38-41.

29. Тетенев Ф.Ф., Бодрова Т.Н., Макаров В.М. Биомеханика дыхания при кардиогенном застое в легких. Томск: Изд-во Томск. ун-та; 1993.

30. Пат. № 2262888 Россия. Способ определения тканевого неэластического сопротивления легких / Тетенев Ф.Ф., Бодрова Т.Н., Месько П.Е. и др. // Бюл. открытий и изобрет. 2005; 30.

31. Пат. №2274417 Россия. Способ определения тканевого неэластического сопротивления легких / Тетенев Ф.Ф., Бодрова Т.Н., Левченко А.В. и др. // Бюл. открытий и изобрет. 2008; 11.

32. Агеева Т.С. Клинико-функциональная характеристика и оптимизация диагностики внебольничных пневмоний: Автореф. дис. ... д-ра мед. наук. Томск; 2009.

33. Пат. № 2221482 Россия. Способ определения величины механической активности легких / Тетенев Ф.Ф., Бодрова Т.Н., Тетенев К.Ф. // Бюл. открытий и изобрет. 2004; 2.

34. Пат. № 2364330 Россия. Способ определения величины работы дыхания внутрилегочного источника механической энергии при спонтанном дыхании / Тетенев К.Ф., Тетенев Ф.Ф., Бодрова Т.Н. и др. // Бюл. открытий и изобрет. 2009; 23.
35. Пат. № 2364331 Россия. Способ определения величины суммарной работы дыхания внутрилегочного и внелегочного источников механической энергии при спонтанном дыхании / Тетенев К.Ф., Тетенев Ф.Ф., Бодрова Т.Н. и др. // Бюл. открытий и изобрет. 2009; 23.

36. Бодрова T.Н. Механика дыхания при диссеминированном туберкулезе легких: Автореф. дис. ... канд. мед. наук. М.; 1982.

37. Тетенев Ф.Ф., Машуков В.К. Биомеханика дыхания при острой пневмонии. Тер. арх. 1978; 3: 45-49.

38. Биомеханика дыхания при туберкулезе / Стрелис А.К., Тетенев Ф.Ф., Бодрова Т.Н. и др. Томск: Изд-во Томск. ун-та; 1986.

39. Даниленко В.Ю. Вентиляционная функция легких при внебольничной пневмонии: Автореф. дис. ... канд. мед. наук. Томск; 2008.

40. Левченко А.В. Регионарная вентиляция, кровоток, механика дыхания у здоровых людей, больных хроническим бронхитом и бронхиальной астмой: Автореф. дис.... канд. мед. наук. Томск; 1994.

41. Кашута А.Ю. Интегральная и регионарная механика дыхания у здоровых людей и больных хронической обструктивной болезнью легких: Автореф. дис. ... канд. мед. наук. Томск; 2007.

42. Пат. № 2328970 Россия. Способ определения регионарной механической активности легких / Тетенев Ф.Ф., Левченко А.В., Бодрова Т.Н. и др. // Бюл. открытий и изобрет. 2008; 20.

43. Тетенев Ф.Ф., Агеева Т.С., Даниленко В.Ю. и др. Проходимость бронхов при внебольничной пневмонии. Тер. apx. 2007; 3: 48-51.

44. Бодрова Т.Н., Тетенев Ф.Ф., Агеева Т.С. и др. Структура неэластического сопротивления легких при внебольничных пневмониях. Бюл. Сиб. мед. 2006; 3: 69-72.

45. Тетенев Ф.Ф., Агеева Т.С., Кривоногов Н.Г. и др. Общее неэластическое сопротивление легких и проницаемость альвеолярно-капиллярной мембраны при внебольничных пневмониях. Тер. арх. 2009; 3: 43-47.

46. Тетенев $Ф . Ф$. Обструктивная теория нарушения внешнего дыхания. Состояние, перспективы развития (актовая лекция). Бюл. Сиб. мед. 2005; 4: 14-26.

47. Карзилов А.И. Механизмы респираторного эффекта чрезкожной электростимуляции диафрагмы: Автореф. дис. ... канд. мед. наук. Томск; 1994.

48. Карзилов А.И., Тетенев Ф.Ф., Бодрова Т.Н. Влияние респираторной терапии на регуляцию дыхания у больных с бронхообструктивным синдромом и здоровых лиц. Пульмонология 2005; 3: 77-82.

49. Карзилов А.И. Биомеханический гомеостазис аппарата внешнего дыхания, и механизмы его обеспечения в нормальных условиях и при обструктивных заболеваниях легких. Бюл. Сиб. мед. 2007; 1: 13-38.

50. Карзилов А.И. Регуляторное обеспечение устойчивости биомеханики дыхания при обструктивных заболеваниях легких: Автореф. дис. ... д-ра мед. наук. Барнаул; 2009.

\section{Информация об авторе}

Тетенев Федор Федорович - д. м. н., проф., зав. кафедрой пропедевтики внутренних болезней СибгМУ; тел.: (3822) 53-07-27; e-mail: ftetenev@list.ru 